CARVALHO, T.F. et al. Ocorrência de quimiodectoma em tronco carotídeo de cão. PUBVET, Londrina, V. 5, N. 31, Ed. 178, Art. 1202, 2011.

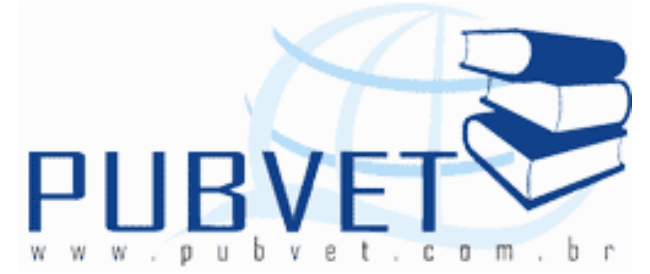

PUBVET, Publicações em Medicina Veterinária e Zootecnia.

\title{
Ocorrência de quimiodectoma em tronco carotídeo de cão
}

\footnotetext{
Tatiane Furtado de Carvalho ${ }^{1}$,Humberto Eustáquio Coelho ${ }^{2}$,Flavia Maria Esteves Machado ${ }^{3}$, Hélio Alberto ${ }^{4}$, Carla Cunha Locce ${ }^{5}$, Karina Danielle Cobo Silva ${ }^{5}$, Claúdio Henrique Gonçalves Barbosa ${ }^{1}$, Aline Oliveira Coelho Magalhães 6
}

\footnotetext{
${ }^{1}$ Residente em Patologia Animal - Hospital Veterinário de Uberaba (HUV) - Av. do Tutunas, 720 Bairro Tutunas Uberaba - MG 38061-500 Brasil. ${ }^{2}$ Professor de Patologia Animal - Universidade de Uberaba (UNIUBE). ${ }^{3}$ Professora de Epidemiologia e Zoonoses - UNIUBE.

${ }^{4}$ Farmacêutico e Técnico do Laboratório de Anatomia Patológica do HVU.

${ }^{5}$ Acadêmico do curso de Medicina Veterinária da UNIUBE

${ }^{6}$ Médica veterinária, Mestre em Patologia Animal, Professora de Patologia geral da UNIUBE.
}

\section{Resumo}

Quimiodectoma é a neoplasia maligna ou benigna, comumente localizada na base do coração, originárias de células quimiorreceptoras. O presente trabalho relata um caso de quimiodectoma em um cão macho da raça Fila Brasileiro de 11 anos. O animal apresentava tosse freqüente, quadros de dispnéia e edema nos membros. Na necropsia diagnosticou-se a causa como sendo quimiodectoma no tronco carotídeo, com metástases no pulmão, fígado, baço e pâncreas. A causa do quimiodectoma é desconhecida, porém até o momento 
CARVALHO, T.F. et al. Ocorrência de quimiodectoma em tronco carotídeo de cão. PUBVET, Londrina, V. 5, N. 31, Ed. 178, Art. 1202, 2011.

tem se observado características comuns como a presença de uma doença respiratória crônica, associada a neoplasias.

Palavras-chave: cão, tumor, quimiodectoma, corpo carotídeo.

\title{
Occurrence of carotid body chemodectomas in dog
}

\begin{abstract}
Chemodectomas are malignant or benign neoplasms of chemoreceptor cells, which are commonly located in the base of the dog's heart. This paper reports a case of chemodectoma in an 11 years old male dog of Fila Brasileiro breed, in Uberaba city. The animal has a frequent cough, dyspnea and members edema. Carotid body chemodectoma was diagnosed on lung areas, liver, spleen and pancreas metastases. The chemodectoma causes still unknown, but most of affected animals, has a chronic respiratory disease, associated with the neoplasms.
\end{abstract}

Keyword: chemodectoma, carotid body, dog, neoplasms.

\section{INTRODUÇÃO}

A respiração e a circulação são reguladas por rede de órgãos quimiorreceptores que monitoram parâmetros sanguíneos tais como $\mathrm{pH}$, tensão de oxigênio e de $\mathrm{CO}_{2}$. Tal rede está em comunicação com o tronco encefálico. O tecido quimiorreceptor está presente em diversos locais do organismo, como no corpo aórtico e carotídeo, no pâncreas, no gânglio nodoso do nervo vago, na veia jugular interna abaixo do ouvido médio, nos gânglios ciliares da órbita e no glomo da jugular ao longo do ramo recorrente do nervo glossofaríngeo (CAPEN, 2002; DEIM et al., 2007; CAPEN, 1998; HEADLEY et al., 2009). Os principais órgãos nessa rede são o corpo aórtico e o corpo carotídeo (CHIQUITO et al., 1998).

Os corpos aórtico e carotídeo são órgãos quimiorreceptores sensitivos a variações no pH sanguíneo, tensão de oxigênio e conteúdo de dióxido de 
CARVALHO, T.F. et al. Ocorrência de quimiodectoma em tronco carotídeo de cão. PUBVET, Londrina, V. 5, N. 31, Ed. 178, Art. 1202, 2011.

carbono, de modo que auxiliam na regularização da respiração e circulação (CAPEN, 1990; 1993; 1998; JONES et al., 1996; 2000). Baseados nessa função, estes tumores foram chamados de quimiodectomas (JONES et al., 1996; 2000), mas esta denominação parece não ser a mais adequada, pois são tumores do sistema paraganglionar e não de células quimiorreceptoras (SOUSA et al., 2000). Do ponto de vista embriológico a nomenclatura mais apropriada é paraganglioma. Outros termos, tais como, tumor do corpo aórtico e carotídeo, tumor glômico, quimiodectoma e tumor não cromafim são termos menos acurados (DAVIDOVIC et al., 2005).

Eles estimulam os movimentos respiratórios e elevam a pressão arterial e a frequência cardíaca (MUZZI et al., 2006). Os corpos aórtico e carotídeo podem iniciar um aumento na profundidade, volume minuto, e taxa respiratória, por intermédio do sistema nervoso parassimpático, o que resulta em aumento da taxa cardíaca e elevação da pressão sanguínea arterial por intermédio do sistema nervoso simpático. Embora a origem embrionária dos órgãos quimiorreceptores não seja precisamente conhecida, existe considerável evidência que sugere que eles se originam das células mesodérmicas perivasculares que são invadidas por células de origem neuroectodérmica (PRYSE-DAVIS et al., 1964 apud CAPEN, 1990). Devido a sua natureza neuroendócrina, têm sido classificados como tumores neuroendócrinos ou apudomas (CAPEN, 2002).

O corpo carotídeo é uma estrutura ovóide, irregular, de coloração rósea, que mede aproximadamente $6 \times 4 \times 2 \mathrm{~mm}$ (ROBBINS et al., 1986), elíptico e variando a coloração em amarronzada (KAMAN et al., 1999; RABL et al.,1993), localizado bilateralmente na bifurcação da artéria carótida, intimamente ligado à adventícia desses vasos. A seu pólo superior, chegam ramos nervosos simpáticos e do nervo glossofaríngeo. Dessa mesma região, partem pequenos ramos venosos que desembocam no tronco tireolinguofacial (ROBBINS et al., 1986). É irrigado por ramos da artéria carótida externa e comum (KAMAN et al., 1999; RABL et al.,1993). 
CARVALHO, T.F. et al. Ocorrência de quimiodectoma em tronco carotídeo de cão. PUBVET, Londrina, V. 5, N. 31, Ed. 178, Art. 1202, 2011.

MUZZI et al. (2006) e FRANÇA et al. (2003), explicam que as neoplasias só se desenvolvem nos quimiorreceptores do corpo carotídeo e do aórtico, localizados na adventícia da bifurcação da artéria carótida comum.

O tumor de corpo carotídeo é também conhecido como quimiodectoma ou paraganglioma (CRUZ, 2008). Os paragangliomas do corpo aórtico e carotídeo são neoplasias raras que se originam das células neuroendócrinas da paraganglia no sistema parassimpático (JONES et al., 1996; 2000). São compostas por células não-cromafins (LÁZARO et al., 2003), originárias da crista neural (NOBLE et al., 1997; GALVÃO et al., 2004), apresentando as mesmas características histológicas do tecido normal (CRUZ, 2008). Esse grupo de células está associado ao sistema nervoso autônomo (LÁZARO et al., 2003), de onde também são derivados o gânglio simpático e a medula adrenal (PÁVAI et al., 2001).

O quimiodectoma é geralmente benigno, com baixa freqüência de recidiva ou metástase, mas a presença de massas de diferentes sítios simultaneamente é relatada. A neoplasia se caracteriza pela presença de células ovais ou poliédricas, com núcleo escuro centralizado, citoplasma finalmente granular e formando aglomerados celulares separados por trabéculas fibrosas. O paciente pode ser assintomático, sendo o tumor encontrado em exames radiográficos de rotina ou com achados de necropsia, mas pode causar alterações na pressão sanguínea e causar a compressão de nervos e outras estruturas (GARRIDO et al., 2008).

Os quimiodectomas de corpo aórtico são cinco vezes mais comuns que os de corpo carotídeo, possuem probabilidade de fazer metástase distante de $12 \%$, sendo freqüente a ocorrência de tumores primários concomitantes, como carcinomas tireoideanos e tumores testiculares. Ocorrem mais em machos da espécie canina, com idade superior a oito anos, das raças Boxer e Boston Terrier (MUZZI et al., 2006).

Tais raças braquicefálicas descendem dos buldogues. A alta incidência de quimiodectoma nessas raças seria devido a fatores fenotípicos e genotípicos - 
CARVALHO, T.F. et al. Ocorrência de quimiodectoma em tronco carotídeo de cão. PUBVET, Londrina, V. 5, N. 31, Ed. 178, Art. 1202, 2011.

estando entre estes, anomalias das vias respiratórias que sujeitam os animais a esforço respiratório crônico (CHIQUITO et al., 1998).

Altitudes inferiores a 1.000 metros excluem a possibilidade dos quimiodectomas terem sido induzidos por hipóxia crônica imposta por baixa tensão de oxigênio (CHIQUITO et al., 1998).

Condições que produzem hipóxia crônica e transmissão autossômica dominante de penetrância incompleta são consideradas os principais fatores etiológicos em humanos (RABL et al., 1993; SCHMID et al., 1995). A maioria desses tumores tem comportamento benigno e cresce lentamente. Em aproximadamente $2 \%$ dos casos, os tumores são malignos, sem marcadores tumorais, e a disseminação pode ocorrer até vários anos após o diagnóstico (FRANÇA et al., 2003).

Um higroma cotovelar (seroma cotovelar, bursite olecraniana) é uma cavidade preenchida por fluido, circundada por tecido conjuntivo fibroso denso, que surge na face lateral do olecrano. Causado por traumatismo crônico, ele quase sempre ocorre bilatelramente como um inchaço indolor (FOSSUM, 2002). A lesão tecidual resulta em isquemia dos tecidos moles situados sobre o osso, necrose celular, e na formação de parede de tecido conjuntivo que circunda o espaço repleto de líquido. Os higromas são pseudocistos, e não cistos verdadeiros, porque estas formações não possuem revestimento epitelial ou sinovial. O líquido que ocupa a cavidade é similar a transudato sérico (SLLATER, 1998). A maioria dos higromas cotovelares ocorre em cães jovens (6 a 18 mese de idade) de raças grandes, antes de se formar um calo protetor sobre a proeminência óssea; no entanto, eles podem ocorrer em animais idosos com doença neuromuscular. Alguns cães com pele fina e gordura subcutânea esparsa ficam predispostos a higromas (FOSSUM, 2002).

O objetivo do presente relato é descrever um caso de quimiodectoma de corpo carotídeo em um cão, por ser de ocorrência rara, demonstrando as principais características fisiológicas, a etiopatogenia, exame físico, sinais clínicos, diagnóstico, prognóstico e tratamento. 
CARVALHO, T.F. et al. Ocorrência de quimiodectoma em tronco carotídeo de cão. PUBVET, Londrina, V. 5, N. 31, Ed. 178, Art. 1202, 2011.

\section{Fisiologia}

Nos corpos aórticos e carotídeos estão presentes quimiorreceptores periféricos que são responsáveis pela resposta respiratória a hipóxia (CUNNINGHAM, 1999), sendo os únicos locais onde a pressão parcial de oxigênio pode ser detectada (SWENSON; REECE, 1996). A remoção dos quimiorreceptores periféricos elimina a resposta respiratória a hipóxia (CUNNINGHAM, 1999), causando hipoventilação crônica (PCO2 aumentada em 5 - $10 \mathrm{mmHg}$ ), indicando que os corpos carotídeos suprem uma parte importante da condução tônica na ventilação de repouso nas condições normais de oxigenação (SWENSON; REECE, 1996).

Os corpos aórtico e carotídeos parecem ser mais ativos no feto e pouco importantes no adulto (CUNNINGHAM, 1999), e recebem um generoso suprimento sanguíneo, tendo alta captação de oxigênio por unidade de peso (HÖGLUND, 1967, KOBAIASHI, 1968). Microscopicamente, a paraganglia é composta pelas células do glomo (BURGGREN et al., 2000; BROWN et al., 2003) ou tipo I, que têm origem neuroectodérmica e contêm grânulos neurosecretórios (CUNNINGHAM, 1999), podendo elaborar catecolaminas no corpo normal e em estado neoplásico (DAVIS et al., 1997), em especial a dopamina (CUNNINGHAM, 1999), e também serotonina (DELLMAN; EURELL, 1998). As células do tipo I são recobertas pelas células de sustentação ou tipo II (BURGGREN et al., 2000). As células de sustentação são relatadas como células satélites do gânglio autônomo, portanto são desprovidos de grânulos neurosecretórios (DAVIS et al., 1997). Em humanos, as células paraganglionares são capazes de sintetizar e armazenar substâncias vasoativas e neurotransmissores como as catecolaminas, dopamina, epinefrina e norepinefrina, assim como uma variedade de hormônios, incluindo serotonina, gastrina e somatostatina (GALVÃO et al., 2004; PÁVAI et al., 2001). 
CARVALHO, T.F. et al. Ocorrência de quimiodectoma em tronco carotídeo de cão. PUBVET, Londrina, V. 5, N. 31, Ed. 178, Art. 1202, 2011.

\section{Etiopatogenia}

Embora a origem dos paragangliomas seja desconhecida, sugere-se que uma predisposição genética agravada por hipoxia crônica, poderia explicar a alta incidência em certas raças de cães braquiocefálicas ao desenvolvimento de tumores do corpo aórtico e carotídeo (HAYES; SASS, 1975; HAMILTON, 2003; CAPEN, 1990, 1993 e 1998; CARUSO et al., 2002; ZIMMERMAN et al., 2000). Sugere-se que à conformação anatômica do trato respiratório superior das raças braquiocefálicas (anomalias das vias respiratórias) poderia favorecer um esforço respiratório crônico (HAYES, 1975; BROWN et al., 2003; PALTRINIERI et al., 2004).

A predisposição genética associada a condições que levem a hipóxica crônica constitui um fator importante no desenvolvimento do tumor (CAPEN, 2002; CAVALCANTI et al., 2006). As raças braquicefálicas possuem orifícios nasais pequenos e um palato mole longo, estando mais predispostas, portanto, ao desenvolvimento de hipoxemia sob condições de esforço respiratório prolongado (HAYES; FRAUMENI, 1974). A maior incidência do tumor em cães das raças boxer e boston terrier pode apontar também para uma possível predisposição familiar, embora o tumor já tenha sido descrito em outras raças com menor freqüência (CAVALCANTI et al., 2006; YATES, LESTER; MILLS, 1980).

A braquiocefalia parece não ser um fator contribuinte em gatos (WILLIS, 2001). Os corpos aórtico e carotídeo participam na regulação reflexa da ventilação e tensão arterial, nos casos em que há diminuição da $\mathrm{PO} 2$, do pH, ou aumento da PCO2 (SOUSA et al., 2000; BURGGREN et al., 2000). O estímulo crônico por um fator ambiental (ex: elevadas altitudes), podem levar a hiperplasia do corpo aórtico e carotídeo, que gera neoplasia (HADLOW, 1986; EDWUARDS et al., 1971; CARUSO et al., 2002; CORCHÓN e LOPEZ, 2002; BROWN, 2003; ARAÚJO et al., 2005), pois há um aumento no número das células (CHEVILLE, 1994). 
CARVALHO, T.F. et al. Ocorrência de quimiodectoma em tronco carotídeo de cão. PUBVET, Londrina, V. 5, N. 31, Ed. 178, Art. 1202, 2011.

Tem sido relatada uma alta incidência em humanos e bovinos que vivem em áreas montanhosas (PALTRINIERI et al., 2004). HADLOW (1986) relata severa hiperplasia nos corpos carotídeos de 20 bovinos que viviam a uma altitude de 4370 metros.

Os paragangliomas são frequentemente benignos (CAPEN, 1990; JONES et al.,1996; ETTINGER; FELDMAN, 1997; HAMILTON, 2003; KOISHI et al., 2005), entretanto, carcinomas têm sido relatados (CAPEN, 1990; 1993). Em cães, um estudo revelou a invasão local em $43 \%$ dos casos e metástases em $22 \%$ dos casos de cães com quimiodectoma (PATNAIK et al., 1975).

Paragangliomas do corpo aórtico em animais tendem a ser mais benignos, que os tumores do corpo carotídeo e crescem lentamente por expansão (JONES et al., 1996; 2000). Paragangliomas do corpo carotídeo se originam próximo à bifurcação da artéria carótida comum na área cervical cranial (CAPEN, 1990), e aproximadamente $65 \%$ dos tumores do corpo carotídeo, ocorrem concomitantemente a tumores do corpo aórtico (CAPEN, 1990; JONES et al., 1996; 2000). Eles usualmente aparecem como uma massa unilateral de crescimento lento, e só raramente se desenvolvem em ambos os lados no mesmo animal. Os adenomas do corpo carotídeo são firmes, brancos, bem encapsulados, e com áreas esparsas de hemorragia, sendo extremamente vascular (CAPEN, 1990; 1993; 1998).

Biopsia e completa excisão cirúrgica são frequentemente difíceis, devido a intensa vascularização e íntima relação do tumor com o maior tronco arterial do pescoço (CAPEN, 1990; 1993; 1998).

Tumores malignos do corpo carotídeo são maiores (em torno de $12 \mathrm{~cm}$ de diâmetro) e são mais grosseiramente multinodulares que os adenomas. Várias áreas de hemorragia e degeneração cística estão presentes dentro do tumor. Embora os carcinomas pareçam ser encapsulados, células tumorais invadem a cápsula e a parede de vasos sanguíneos e linfáticos adjacentes. A veia jugular externa, vários nervos cranianos e bifurcação da artéria carótida, podem ser incorporados pela neoplasia. Tumores maiores resultam em extensão dorsolateral com desvio da traquéia (CAPEN, 1990; 1993; 1998). 
CARVALHO, T.F. et al. Ocorrência de quimiodectoma em tronco carotídeo de cão. PUBVET, Londrina, V. 5, N. 31, Ed. 178, Art. 1202, 2011.

Como os tumores do corpo carotídeo tendem a ser mais malignos, metástases ocorrem em 30\% dos casos e ocorrem comumente em pulmões, brônquios, linfonodos mediastínicos, fígado, pâncreas e rins (DEAN; STRAFUSS, 1975; SANDER; WHITENACK，1970; CAPEN，1993; 1998). Metástases de órgãos parênquimatosos, tais como os rins, podem ser extensivas e quase obliterar o órgão afetado (CAPEN, 1990; 1993; 1998). Metástases vertebrais isoladas são raras e mais comumente associadas à paragangliomas cervicais (LÁZARO et al., 2003). Em gatos os paragangliomas apresentam crescimento lento e localmente invasivo, com moderado potencial metastático. Em um estudo três de seis gatos tiveram metástases: um no linfonodo esternal, e dois no pericárdio, epicárdio, miocárdio e pulmões (CARUSO et al., 2002).

\section{Exame físico e sinais clínicos}

Os tumores do corpo aórtico e carotídeo em animais não são funcionais (não secretam excesso de hormônio na circulação), mas as lesões por ocupação de espaço podem resultar em uma variedade de sinais clínicos (CAPEN, 1990; 1993; 1998). O quadro clínico pode ser pobre, principalmente quando o tumor não alcançou tamanho suficiente para afetar estruturas vasculares /ou nervosas (SOUZA et al., 2000), sendo muitas vezes achados acidentais de necropsia (GRACIANO et al., 2009).

Tumores do corpo carotídeo podem ser evidenciados pela regurgitação, disfagia, fístula arteriovenosa no pescoço e massa cervical palpável (HAMILTON, 2003). Neoplasias maiores interferem na deglutição devido à pressão no esôfago, e resulta em distúrbios circulatórios pela compressão de veias maiores no pescoço. Dispnéia e tosse têm sido observadas em cães com tumores malignos do corpo carotídeo, que têm múltiplas metástases pulmonares (CAPEN, 1990; 1993; 1998). Em ambos os tipos, pode ocorrer hemorragia aguda devido à invasão por vasos sanguíneos, podendo causar 
CARVALHO, T.F. et al. Ocorrência de quimiodectoma em tronco carotídeo de cão. PUBVET, Londrina, V. 5, N. 31, Ed. 178, Art. 1202, 2011.

morte súbita. A invasão local de vasos sanguíneos ocorre em até $50 \%$ dos pacientes (HAMILTON, 2003).

\section{Diagnóstico}

A hematologia e a bioquímica sérica podem não ser dignas de nota (PALTRINIERI et al., 2004). No hemograma pode-se evidenciar anemia decorrente de sangramento. As enzimas hepáticas, uréia e creatinina podem estar elevadas em casos de metástases em fígado ou rins (HAMILTON, 2003).

$\mathrm{Na}$ medicina veterinária o diagnóstico por imagem é muitas vezes limitado, porque só estão disponíveis radiografia e ultrasonografia. A tomografia computadorizada já se encontra disponível em alguns centros veterinários, mas não é realizada rotineiramente. A ressonância magnética e a angiografia quando ocorrem, são de modo experimental. Na medicina humana a angiografia, tomografia computadorizada (DAVIDOVIC et al., 2005) e ressonância nuclear magnética, (LÁZARO et al., 2003) são as mais utilizadas.

No caso de tumor do corpo carotídeo, pode-se observar uma massa na região cervical, próximo à bifurcação carotídea. Neste caso, as radiografias são mais importantes para avaliar a presença de metástase em órgãos, vértebras ou ossos (LÁZARO et al., 2003). Radiografias abdominais podem ser úteis para a detecção de metástases em fígado ou rins.

O paraganglioma do corpo carotídeo pode aparecer ao ultrasom como uma lesão nodular na bifurcação carotídea, hipoecogênica ou isoecogênica e bem delimitada (RAO et al., 1999). Ao Doppler o achado típico desta massa é de rica vascularização, mostrando baixa resistência arterial (SOMA et al., 2002). Deslocamento dos vasos carotídeos, dilatação e tortuosidade dos vasos do pescoço podem ser evidenciadas junto a estas lesões (RAO et al., 1999).

O diagnóstico de paragangliomas pode ser confirmado por meio de biopsia excisional ou biopsia aspirativa (PALTRINIERI et al., 2004). Atualmente prefere-se a prática de biopsia aspirativa, que pode muitas vezes conduzir ao diagnóstico quando a história clínica, sinais clínicos e achados de necropsia são 
CARVALHO, T.F. et al. Ocorrência de quimiodectoma em tronco carotídeo de cão. PUBVET, Londrina, V. 5, N. 31, Ed. 178, Art. 1202, 2011.

compatíveis. A punção com agulha fina da massa é um método menos invasivo que não requer anestesia geral. A punção da massa deve ser guiada por intermédio de ultrasonografia, para evitar danos às estruturas adjacentes e hemorragias potenciais (ZIMMERMAN et al., 2000).

A histopatologia é realizada após a remoção completa da massa ou necropsia. Biopsia é frequentemente difícil, devido a intensa vascularização e íntima relação do tumor com grandes vasos (CAPEN, 1990; 1993; 1998). As células tumorais do corpo aórtico e carotídeo assemelham-se a todas àquelas do tecido quimiorrreceptor normal, mas falta uma relação normal com elementos de sustentação, neurais e vasculares. As células tumorais do quimiodectoma são usualmente bem diferenciadas (JONES et al., 1996), discretas, cubícas a poliédricas, dispostas em lençóis compactos e com membranas celulares indistintas (CAPEN, 1990). O núcleo é centralizado (CAPEN, 1990), esférico a ligeiramente oval, contendo cromatina pontilhada, e um único e proeminente nucléolo (ZIMMERMAN et al., 2000; CARUSO et al., 2002). O citoplasma é levemente eosinofílico, esférico, podendo ser granular ou vacuolar (JONES et al., 1996), com marcada ausência de delimitação celular (CARUSO et al., 2002; CAPEN, 1990;1993).

Como os quimiodectomas se originam das células neuroendócrinas (paraneurônios) da paraganglia, essas células, assemelham-se àquelas da medula adrenal (JONES et al., 1996; 2000). As características histológicas das neoplasias quimiorreceptoras (quimiodectomas) são essencialmente semelhantes quer elas sejam derivadas do corpo aórtico ou carotídeo. As células quimiorreceptoras neoplásicas são subdivididas dentro de lóbulos por trabéculas ramificantes proeminentes de tecido conjuntivo, que é originário da cápsula fibrosa. Eles são adicionalmente subdivididos em ninhos menores ou finos septos que contêm fibras colágenas, reticulina e pequenos capilares. As células neoplásicas são usualmente alinhadas ao longo e ao redor de pequenos capilares (CAPEN, 1990; 1993; 1998). Achados histológicos relevantes incluem a proliferação neoplásica das células poliédricas densamente acondicionadas em pacotes ou folhas separadas por finas trabéculas fibrovasculares (CARUSO 
CARVALHO, T.F. et al. Ocorrência de quimiodectoma em tronco carotídeo de cão. PUBVET, Londrina, V. 5, N. 31, Ed. 178, Art. 1202, 2011.

et al., 2002). Grânulos cromafins não podem ser demonstrados no citoplasma das células que compõem os quimiodectomas, ao contrário dos feocromocitomas da medula adrenal (CAPEN, 1990). Geralmente se evidencia poucas figuras de mitose, raras células gigantes multinucleadas, macrófagos e agregados linfóides periféricos (PALTRINIERI et al., 2004). Áreas focais de hemorragias por rompimento de vasos de parede fina e áreas de necrose de coagulação dentro da região central do tumor (DAVIS et al., 1997) são achados consistentes de quimiodectomas (CAPEN, 1990). Células tumorais freqüentemente invadem os vasos sanguíneos e linfáticos com formação de êmbolos (CAPEN, 1990; PALTRINIERI et al., 2004). Os tumores no corpo carotídeo são bastante vascularizados e têm numerosas arteríolas musculares, veias maiores de parede fina, e uma abundante rede de capilares no tecido conjuntivo do septo (CAPEN, 1990).

\section{Diagnóstico diferencial}

O principal diagnóstico histológico diferencial são as neoplasias tireoidianas ectópicas com arranjo sólido, geralmente caracterizadas por conter células menores, não consistentemente subdivididas em pequenos ninhos por faixas finas de tecido conjuntivo, estroma menos proeminentes e células gigantes tumorais infreqüentes (CAPEN, 2002).

\section{Prognóstico}

A alta vascularização, localização e íntima relação do tumor com estruturas nobres (vasos da cavidade torácica e pescoço) tornam o prognóstico desfavorável, pois a maioria dos pacientes não se encontra em condições favoráveis para suportar uma intervenção cirúrgica, ou porque apresentam complicações posteriores à cirurgia, ou morrem dias após a cirurgia. No caso de tumor do corpo carotídeo, a morbidade pode ser alta quando são ressecados e pode haver alterações dos pares cranianos, disfagia, obstrução 
CARVALHO, T.F. et al. Ocorrência de quimiodectoma em tronco carotídeo de cão. PUBVET, Londrina, V. 5, N. 31, Ed. 178, Art. 1202, 2011.

da via aérea, invasão à base do crânio (CORCHÓN; LOPEZ, 2002.), hemiplegia ou paresia da língua (SOUZA et al., 2000).

\section{Tratamento}

O método essencial no tratamento de paragangliomas do corpo carotídeo também é cirúrgico, pois quando o tumor é completamente removido, as recorrências são pouco comuns. Eventualmente a artéria carótida comum pode ser sacrificada durante o procedimento cirúrgico, especialmente em casos de lesões grandes, com comportamento invasivo ou maligno. A radioterapia teve sucesso como terapia adjuvante à cirurgia em dois cães com tumor do corpo carotídeo (OBRADOVICH et al., 1992). O tratamento quimioterápico destes tumores ainda não foi descrito. Doxorrubicina e ciclofosfamida podem ser usados em casos de tumores metastáticos, havendo relato de remissão parcial em um cão com tumor do corpo carotídeo, que sobreviveu por 15 meses (HAMILTON, 2003).

É importante realizar exame físico, radiográfico e se possível ultrasonográfico a cada três meses. O animal deve ser monitorado quanto à recidiva e metástases (GRACIANO et al., 2009).

\section{RELATO DE CASO}

Um cão macho, 11 anos de idade, da raça Fila Brasileiro, $39 \mathrm{~kg}$, foi encaminhado ao Hospital Veterinário de Uberaba/ MG, pois apresentava tosse seca freqüente, dificuldade respiratória com quadros de dispnéia e edema em todos os membros.

No exame físico o animal se apresentava em decúbito esternal, verificouse creptação grossa e sons cardíacos abafados na auscultação torácica, mucosas levemente pálidas com freqüência cardíaca $80 \mathrm{bpm}$ e respiratória $40 \mathrm{mpm}$. Foi solicitado exame radiológico de tórax que apresentou neoplasia pulmonar primária. Durante o atendimento o animal veio a óbito. 
CARVALHO, T.F. et al. Ocorrência de quimiodectoma em tronco carotídeo de cão. PUBVET, Londrina, V. 5, N. 31, Ed. 178, Art. 1202, 2011.

Durante a necropsia realizada no Laboratório de Anatomia Patológica do HVU, os achados macroscópicos foram presença de higroma cotovelar nos membros anteriores (Figura 01), edema nos membros (Figura 02), quantidade aumentada de líquido nas cavidades, abdominal e torácica, denominadas de hidroperitônio e hidrotórax respectivamente; presença de nódulo no tronco carotídeo medindo aproximadamente $9 \times 6 \mathrm{~cm}$ (Figura 03); no coração a presença de coágulo cruórico no ventrículo esquerdo, fígado de noz-moscada, baço enrugado denominado de baço exangue, pulmão salpicado com nódulos milimétricos, friáveis, causando elevação na pleura (Figura 04), rins apresentando vários nódulos, de diferentes tamanhos tomando conta do órgão (Figura 04) e cistite purulenta aguda (Figura 05).

Foram coletados fragmentos da massa tumoral presente no tronco carotídeo, nos pulmões e rins para realização do exame histopatológico. Após realização de exame microscópico das lesões obteve-se o diagnóstico final de quimiodectoma no tronco carotídeo (Figura 06), com metástases no pulmão, fígado, baço e pâncreas (Figura 07 e 08).

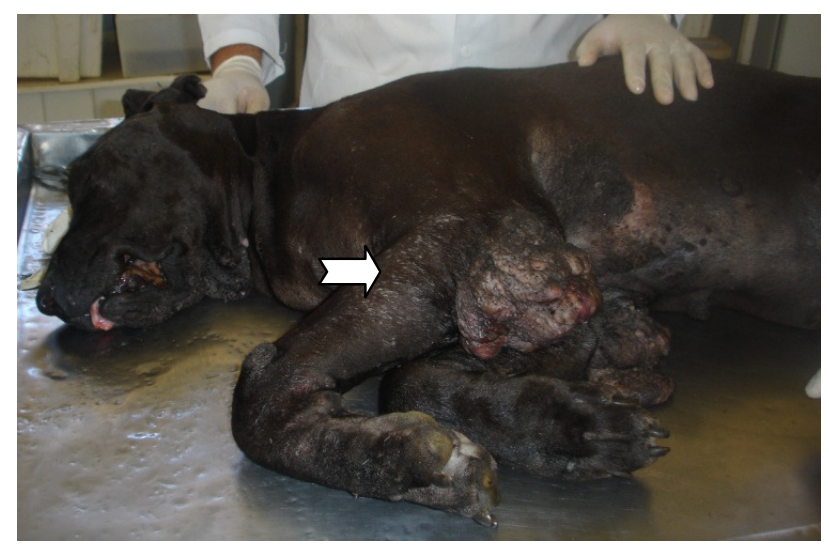

Figura 01 - Canino da raça Fila Brasileiro, de 11 anos de idade. Apresentando higroma cotovelar nos membros anteriores (seta). 
CARVALHO, T.F. et al. Ocorrência de quimiodectoma em tronco carotídeo de cão. PUBVET, Londrina, V. 5, N. 31, Ed. 178, Art. 1202, 2011.

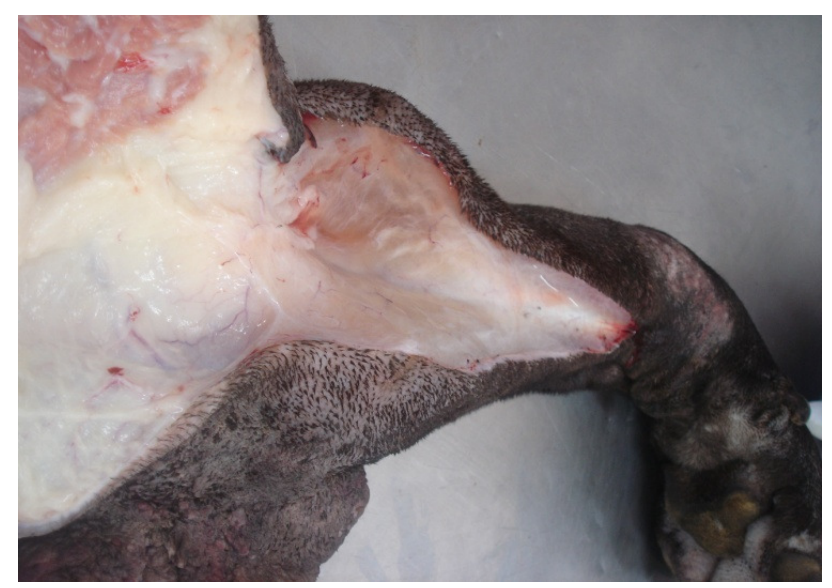

Figura 02 - Cão com membros edemaciados, evidenciando o membro anterior esquerdo bastante edemaciado, com aspecto de gelatina.
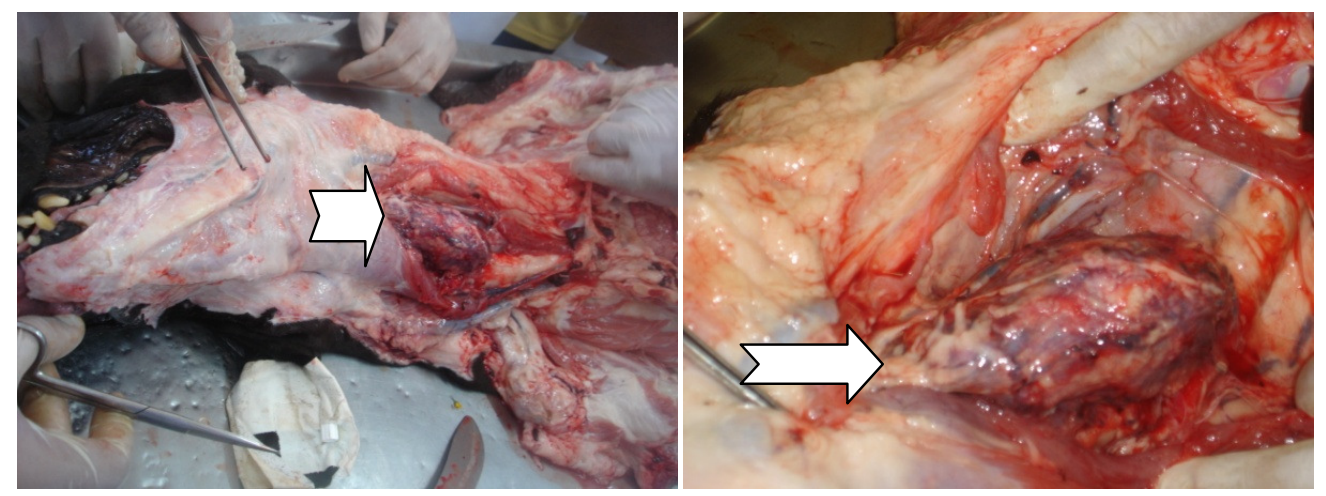

Figura 03 - Animal apresentando quimiodectoma de tronco carotídeo (seta branca), a imagem a direita evidencia melhor essa neoplasia medindo aproximadamente $9 \times 6 \mathrm{~cm}$. 
CARVALHO, T.F. et al. Ocorrência de quimiodectoma em tronco carotídeo de cão. PUBVET, Londrina, V. 5, N. 31, Ed. 178, Art. 1202, 2011.

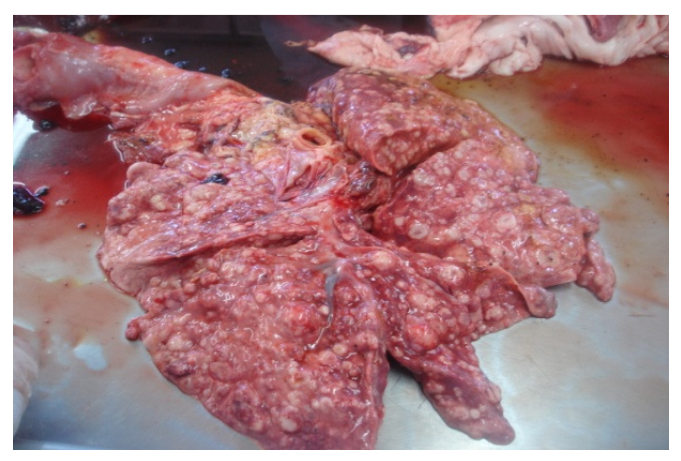

Figura 04 - Cão da raça Fila Brasileiro, de 11 anos de idade, com pulmão salpicado de nódulos milimétricos e friáveis e presença de massas neoplásicas no rim, caracterizando metástase do quimiodectoma de corpo carotídeo para pulmões e rins do animal.

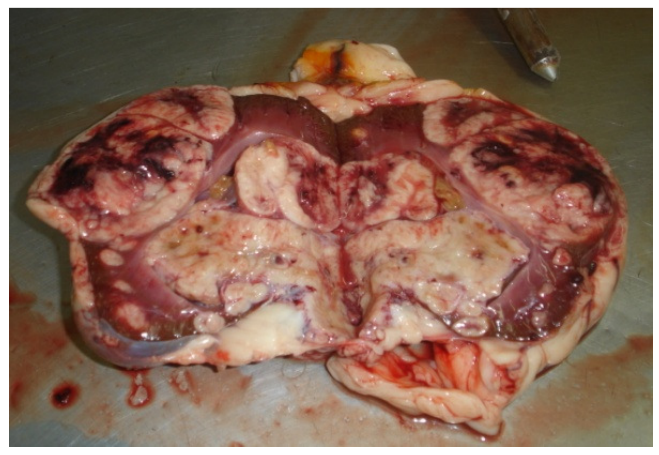

Figura 05 - Bexiga do cão apresentando mucosa hiperemica e exsudato purulento caracterizando uma cistite purulenta aguda. 
CARVALHO, T.F. et al. Ocorrência de quimiodectoma em tronco carotídeo de cão. PUBVET, Londrina, V. 5, N. 31, Ed. 178, Art. 1202, 2011.

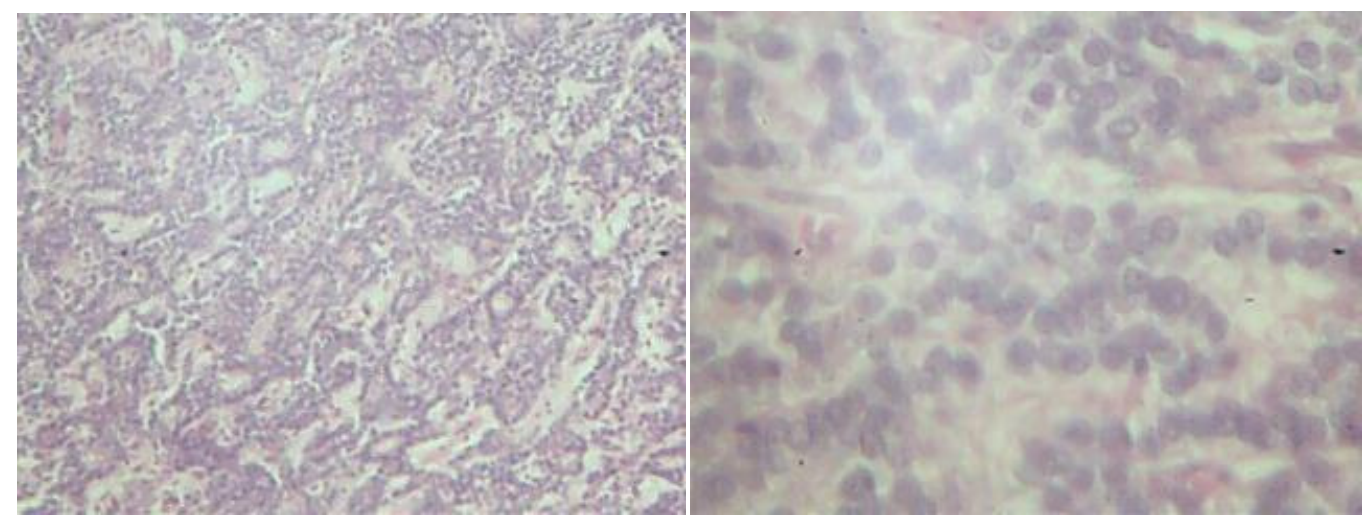

Figura 06 - Microfotografia de quimiodectoma: tumor do tronco carotídeo em cão. Em aumento de 10x e 40x. Evidenciando células redondas com núcleos centrais e redondos. Coloração HE.

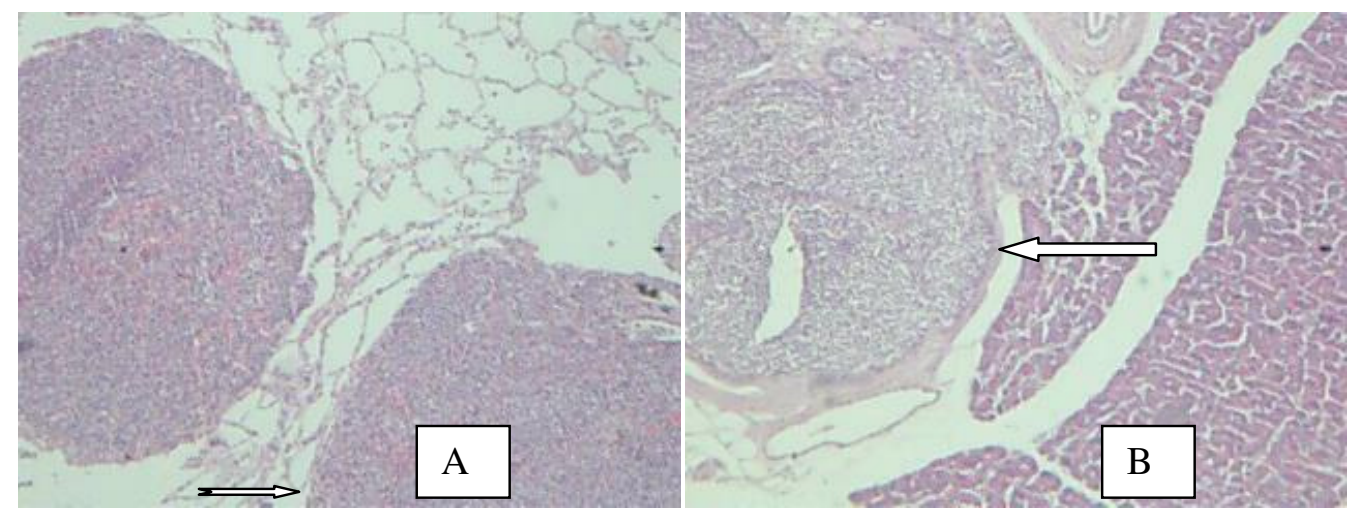

Figura 07 - Microfotografia do quimiodectoma com metástase. Na microfotografia A, evidencia metástase no pulmão (seta), aumento 4x. Em B, observar metástase no pâncreas (seta) aumento de 4x. Coloração H\&E. 
CARVALHO, T.F. et al. Ocorrência de quimiodectoma em tronco carotídeo de cão. PUBVET, Londrina, V. 5, N. 31, Ed. 178, Art. 1202, 2011.

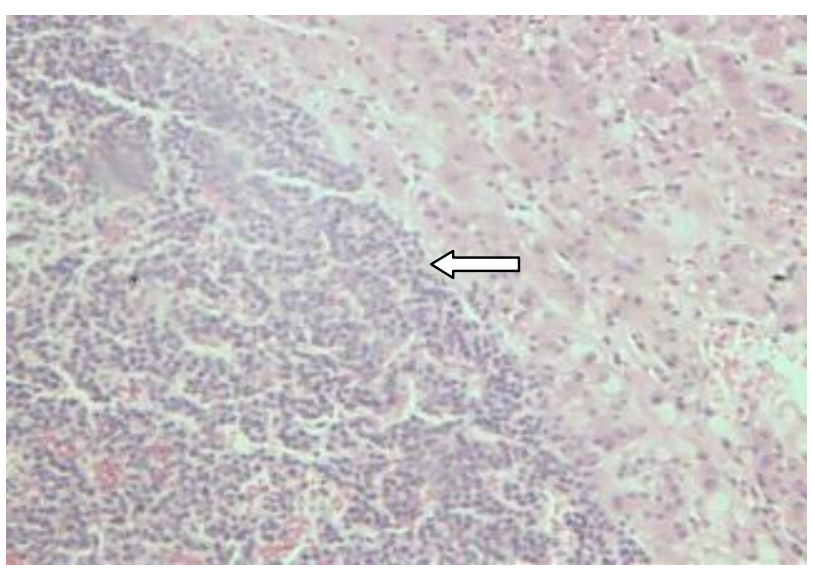

Figura 08 - Microfotografia do quimiodectoma com metástase no fígado (seta), aumento 20x. Coloração H\&E.

\section{DISCUSSÃO}

Concordando com MUZZI et al.(2006), este animal apresentava algumas das características mais comuns aquelas encontradas em animais com quimiodectoma, como: ser macho, possuir mais de oito anos, possuir metástases em vários outros órgãos e a neoplasia se encontrar em tronco carotídeo, já que na maioria das vezes este se encontra no corpo aórtico.

Os paragangliomas são mais freqüentes em cães machos que fêmeas (BISHOP, 1975; BROWN et al., 2003; PALTRINIERI et al.,2004), numa relação de 7:1 (DEAN e STRAFUSS, 1975 apud ARAÚJO, 2005). Segundo HAMILTON (2003), cães machos têm mais propensão para desenvolver paraganglioma do corpo aórtico, não havendo predileção sexual em casos de paraganglioma do corpo carotídeo. ZIMMERMAN et al. (2000) relataram um caso de paraganglioma em uma fêmea Golden Retriever. HEADLEY et al. (2004) realizaram a necropsia de duas cadelas com paraganglioma, uma da raça Pastor Alemão e outra Rottweiler. HEADLEY et al. (2004), evidenciaram paraganglioma do corpo carotídeo em Pastor Alemão

Os tumores de corpo aórtico em cães são mais freqüentes do que os de corpo carotídeo, ao contrário do que ocorre em seres humanos (WARE, 2002; DEAN; STRAFUSS, 1975). 
CARVALHO, T.F. et al. Ocorrência de quimiodectoma em tronco carotídeo de cão. PUBVET, Londrina, V. 5, N. 31, Ed. 178, Art. 1202, 2011.

Esses tumores desenvolvem-se primariamente em cães (CAPEN, 1990; JONES et al., 1996; 2000; BROWN et al., 2003) e raramente em gatos (CARUSO et al., 2002; BROWN et al., 2003; PALTRINIERI et al., 2003) e vacas (NORDSTOGA, 1966 apud CAPEN, 1990). Entretanto, outras espécies podem ser acometidas, incluindo eqüinos (ZIMMERMAN et al., 2000; DE BARROS; DOS SANTOS apud BROWN et al., 2003) e aves (JONES et al., 1996). Tumores do corpo carotídeo já foram relatados em vacas, gatos e martas (JONES et al., 1996).

Porém, possuía algumas mais incomuns como não ser de uma raça braquicefálica, discordando de CHIQUITO et al. (1998) que relatam a incidência em raças braquicefálicas.

Neste caso é praticamente impossível apontar possíveis causas para o tumor em relação à região de Uberaba- MG onde o animal vivia, com altitude média de 801 metros, que de acordo com CHIQUITO et al. (1998) que provoca um esforço respiratório crônico.

A hipóxia crônica, seja ela causada por doença ou estabelecimento em grande altitude, leva os quimiorreceptores á hiperplasia, que pode progredir para neoplasia. Isso foi dramaticamente demonstrado por ARIAS-STELL e BUSTOS apud HADLOW (1986), que estudaram 20 bovinos vivendo a uma altitude de 4370 metros. Houve severa hiperplasia nos corpos carotídeos desses animais, formando-se focos neoplásicos microscópicos em cinco, e neoplasia macroscópica em três.

Apesar de haver fatores pré disponentes e diferentes espécies apresentando quimiodectoma, esta é considerada rara, comparada a outras neoplasias (CHIQUITO et al., 1998).

As características macroscópicas encontradas neste caso coincidem com as descritas na literatura. Os tumores de corpo carotídeo geralmente são massas solitárias, ovóide, localizado bilateralmente na bifurcação da artéria carótida (ROBBINS et al., 1986), de coloração amarronzada (KAMAN et al., 1999; RABL et al., 1993). 
CARVALHO, T.F. et al. Ocorrência de quimiodectoma em tronco carotídeo de cão. PUBVET, Londrina, V. 5, N. 31, Ed. 178, Art. 1202, 2011.

Os sinais clínicos de tosse seca freqüente e dificuldade respiratória com quadros de dispnéia apresentados pelo animal são consistentes com as manifestações clínicas apresentadas em diversas doenças que acometem o sistema cardiovascular (CAPEN, 2002; MOURA et al., 2006; KISSEBERTH, 2007), e pelo comprometimento pulmonar devido a metástase do quimiodectoma. Embora essa neoplasia seja uma doença de freqüência incomum, deve ser incluído nos diagnósticos diferenciais quando esses sinais estiverem presentes (JARK et al., 2011).

A presença do coagulo cruórico no interior do ventrículo esquerdo do coração do cão em questão, observado no exame anátomo-patológico post mortem, indica uma insuficiência cardíaca congestiva (ICC), justificando a presença do edema nos membros, líquido nas cavidades torácica e abdominal.

Os tumores presentes no corpo carotídeo freqüentemente se manifesta $\mathrm{m}$ na forma de massas sólidas, firmes à palpação e que se desenvolvem na região cervical, ocasionando disfagia, dispnéia e regurgitação, em decorrênc ia da compressão das estruturas presentes nesta região, como traquéia, esôfag o e grandes vasos (SAMPAIO et al., 2008).

O pulmão e rins salpicados de nódulos, caracterizados como metástases, contrariam GRACIANO et al. (2009), que cita os paragangliomas como tumores raros, freqüentemente benignos, que podem raramente produzir metástase.

As características histológicas dos tumores de órgãos quimiorreceptores são similares, visto que derivam do corpo aórtico ou carotídeo (CAPEN, 2002). A avaliação de múltiplas secções histológicas do tumor não revelou a presença de estruturas foliculares primitivas ou folículos preenchidos por colóide, derivados de células neoplásicas foliculares em neoplasias tireoidianas ectópicas (CAPEN, 2002; BALAGUER et al., 1990).

Esse animal apresentou uma lesão conhecida como higroma cotovelar. Cães com displasia coxofemural ou dor decorrente de outra doença ortopédica podem exercer pressão excessiva sobre os cotovelos enquanto se posicionam em decúbito esternal (PIERMATTEI, 1999). Os higromas cotovelares variam em tamanho, ficando maiores e mais espessos com traumatismos repetidos. No 
CARVALHO, T.F. et al. Ocorrência de quimiodectoma em tronco carotídeo de cão. PUBVET, Londrina, V. 5, N. 31, Ed. 178, Art. 1202, 2011.

início, são geralmente estéreis, mas bactérias podem ser introduzidas durante uma aspiração. Higromas infectados ficam doloridos; os indolores e pequenos se tornarão problemas cosméticos persistentes se não forem tratados. Podem ocorrer higromas em outras proeminências ósseas (ou seja, tuberosidade calcânea, trocanter maior, tuberosidade coxal, tuberosidade isquiática, protuberância occipital externa e processos espinhosos dorsais vertebrais torácicos) (SLLATER, 1998).

\section{CONCLUSÕES}

O quimiodectoma de corpo carotídeo se mostrou de caráter malígno, apresentando metástase em vários órgãos. O diagnóstico foi obtido através do exame histopatológico associada às características macroscópicas do tumor apresentadas na necropsia, evidenciando a importância desses exames quando o clínico se depara com tumores no pescoço quando não for possível alcançar um diagnóstico.

\section{REFERÊNCIAS}

ARAÚJO, L. V. et al. Quimiodectoma de corpo aórtico no cão: relato de um caso. In: CONGRESSO SUL AMERICANO DE MEDICINA VETERINÁRIA - UNESA, 5., 2005, Rio de Janeiro. Anais... Rio de Janeiro: UNESA, 2005. Disponível em: <http://www.abma. com.br/2005/internas/trabalhos/pdfs/162.pdf. >. Acesso em: 27 set. 2005.

BROWN, P. J.; REMA, A.; GARTNER, F. Immunohistochemical characteristics of canine aortic and carotid Body Tumours. Journal Veterinary Medicine, a. 50, p. 140-144, 2003.

BURGGREN, W. W.; RANDALL, D.; FRENCH, K. Fisiologia animal (Eckert): mecanismos e adaptações. 2. ed. Rio de Janeiro: Guanabara Koogan, p. 520-521, 2000.

CAPEN, C.C. Sistema endócrino. In: CARLTON, W.W.; MCGAVIN, M.D. Patologia veterinária especial. 2. Ed. Porto Alegre: Artmed, p.266-304, 1998.

CAPEN, C.C. Tumors of the endocrine glands. In: MEUTEN, D.J. Tumors in domestic animals. 4. ed. Iowa: Iowa State Pressp. 607-696, 2002.

CARUSO, K. J. et al. Intrathoracic mass in a cat. Veterinary clinical pathology, Califórnia, USA, v. 31, n. 4, p. 193-195, 2002. 
CAVALCANTI, G.A.O.; MUZZI, R.AL.; BEZERRA JUNIOR, P.S.; NOGUEIRA, R.B.; VARASCHIN, M.S. Fibrilação atrial em cão associada ao quimiodectoma infiltrativo atrial: relato de caso.

Arquivo Brasileiro de Medicina Veterinária e Zootecnia, v. 58, n.6, p. 1043-1047, 2006.

CHEVILLE, N. F. Introdução à patologia veterinária. Rio de Janeiro: Guanabara Koogan, 1994 , p. 250-252.

CHIQUITO, M.; WERNER, P.R.; PACHALY, J.R. Ocorrência de quimiodectoma no primeiro Planalto do Paraná. Arq. ciên. vet. zool. UNIPAR, : 1 (1)ago./dez, Brasil, 1998.

CORCHÓN, A. G.; LOPÉZ R. M. G. Tumores del glomus carotídeo. Serviço de cirurgia oral e maxilofacial, Disponível em: <http://www.icomem.org/prm-2002/links/T._glomus_ texto.pdf>. Acesso em: 27 set. 2002.

CRUZ, C.B.; CAVALCANTI, L.M.; GUEDES, A.J.S.; ANDRADE G.; ABATH, C.G.C.; FERNANDES, R.A. A importância da embolização pré-operatória no tratamento do tumor do corpo carotídeo: relato de caso e revisão da literatura. J. vasc. Arq. bras. v.7 n.2 Porto Alegre jun. 2008.

CUNNINGHAM, J. G. Tratado de fisiologia veterinária. 2. ed. Rio de Janeiro: Guanabara Koogan, p. 478-479, 1999.

DAVIDOVIC, L. B. et al. Diagnosis and treatment of carotid body paraganglioma: 21 Years of Experience at a Clinical Center of Serbia. World Journal of Surgical Oncology, London, n.3, p.10, 2005.

DAVIS, W. P.; KOEHLER, L. K.; BROWN, C. A. Malignant cauda equina paraganglioma in a Cat. Veterinary Pathology, California, v. 34, n. 3, p. 243-246, 1997.

DEAN, M.J.; STRAFUSS, A.C. Carotid body tumors in the dog: a review and report of four cases. Journal of American Veterinary Medical Association, v. 166, p. 1003-1006, 1975.

DEIM, Z.; SZALAY, F.; GLÁVITS, R.; BAUER, A.; CSERNI, G. Carotid body tumor in dog: a case report. Canadian Veterinary Journal, v. 48, n.8, p. 865-866, 2007.

ETTINGER, S. J.; FELDMAN, E. C. Tratado de medicina interna veterinária. São Paulo: Manole, 1997. p. 1179- 1181.

FOSSUM, T.W. Cirurgia de Pequenos Animais. São Paulo,Editora Roca.p. 196-197, 2002.

FRANÇA L.H.G., BREDT C.G., VEDOLIN A., BACK, L.A., STAHLKE Jr H.J. Tratamento cirúrgico do tumor de corpo carotídeo: experiência de 30 anos do Hospital de Clínicas da UFPR. J. Vac. Br. 2 (3): 171-176. 2003.

GALVÃO JUNIOR, A. R. et al. Paraganglioma carotídeo bilateral. Rev. Bras.

Otorrinolaringologia, São Paulo, v. 70, n. 4, jul./ago. 2004.

GARRIDO, E.; JACINTHO, A. P. P.; MAGALHÃES, G. M.; CÂNDIDO, E. M.;VASCONCELOS, R. O. Quimiodectoma em cão - relato de caso. Vet. e Zootec. Supl. v. 15, n. 3,dez., p. 49-50, 2008.

GRACIANO, T. S; BETTINI, C. M; HEADLEY, S. A; MONTEIRO, E. R; QUITZAN, J.G. Paraganglioma de corpo aórtico e carotídeo. Arq. Ciênc. Vet. Zool. UNIPAR,Umuarama, v. 12, n. 2, p. 149-156, jul./dez. 2009. 
HAMILTON, T. A. Quemodectoma. In: TILLEY, L. P.; SMITH JUNIOR, F. W. K. Consulta veterinária em cinco minutos. São Paulo: Manole, p. 540, 2003.

HAYES, H.M.Jr.; FRAUMENI, J.F.Jr. Chemodectomas in dogs: epidemiologic comparisons with man. Journal of National Cancer Institute, v. 52, p. 1455-1458, 1974.

HEADLEY, S. A. et al. Quimiodectoma maligno em um Pastor Alemão. Arquivos de Ciências Veterinárias e Zoologia da Unipar, Umuarama, v. 7, p. 95, 2004. Supl. 1.

HEADLEY, S.A.; BRACARENSE, A.P.; NAKAGAWA, T.; MORENO, K.; PEREIRA, P.M.; REIS, A.C.F Aortic body tumors in dogs from northern Paraná, Brazil. Ciência Rural, v. 39, n.6, p. 19081912, 2009.

JONES, T. C; HUNT, R. D.; KING, N. W. Veterinary pathology. Baltimore: Lippincott Williams e Wilkins, p. 988-989, 1996.

Patologia veterinária. 6. ed, São Paulo: Manole, 2000. p. 1005-1006.

JUBB, K. V. C.; KENNEDY, P. C.; PALMER, N. The endocrine Glands. Pathology of domestic animals. 4. ed, San Diego: Academic Press, p. 267-347, 1993.

KAMAN L, SINGH R, AGGARWAL R, KUMAR R, BEHERA A, KATARIYA RN. Diagnostic and therapeutic approaches to carotid body tumors: report of three cases and review of the literature. Aust N Z J Surg.; 69(12):852-5, 1999.

KISSEBERTH, W.C. Miscellaneous tumors. In: WITHROW, S.J.; VAIL, D.M. Small animal clinical oncology. 4.ed. Missouri: Elsevier, p. 785-823. 2007.

KOISHI, H. U. et al. Paraganglioma cervical bilateral. Arq. Da Fund. Otorrinolaringologia da FMUSP, São Paulo, Disponível em: <http://www.hcnet.usp.br/otorrino/arq7/parag.htm>. Acesso em: 3 maio 2005.

LÁZARO, B. et al. Malignant Paraganglioma with vertebral metastasis. Arq.

Neuropsquiátrico, Rio de Janeiro, v. 61, n. 2-b, p. 463-467, 2003.

Manole LTDA, 1998, p. 1545 - 1549.

MOURA, V.M.B.D.; GOIOZO, P.F.I.; THOMÉ, H.E.; CALDEIRA, C.P.; BANDARRA, E.P. Quimiodectoma como causa de morte súbita em cão - relato de caso. Veterinária Notícias, v.12, n.1, p. 95-99, 2006.

MOUTON, J. E. Tumor of the endocrine glands. Tumors in domestic animals. 3. ed, Los Angeles: California Press, p. 553-639, 1990.

MUZZI, R.A.L.; BEZERRA, P.S; CAVALCANTI, G.A.O.; NOGUEIRA, R.B.; VARASCHIN, M.S. Fibrilação atrial em cão associada ao quimiodectoma infiltrativo atrial: relato de caso. Arq. Bras. Med. Vet. Zootec. v.58, n.6, p.1043-1047, 2006.

NOBLE, E. D.; SMOKER, W. R. K.; GHATAK, N. R. Atypical skull base paragangliomas. AJNR, Oak Brook - IL, n. 18, p. 986-990, 1997.

OBRADOVIC, J. E. et al. Carotid body tumors in the dog: eleven cases (1978 - 1988). J. Vet Intern Med. v. 6, p. 96- 101, 1992. 
PALTRINIERI, S. et al. Pathologic and immunohistochemical findings in a feline aortic body tumor. Veterinary Pathology, California, v. 41, n. 2, p. 195-198, 2004.

PÁVAI, Z. et al. Immunohistochemical features of paragangliomas. J. Cell. Mol. Med. Bucharest - Romania. v. 5, n. 2, p. 311-316, 2001.

PIERMATTEI, D.L.; FLO, G.L. 1999. Manual de Ortopedia e Tratamento de Fraturas dos Pequenos Animais. São Paulo, Editora Manole Ltda. p. 431-432.

RABL H, FRIEHS I, GUTSCHI S, PASCHER O, KOCH G. Diagnosis and treatment of carotid body tumors. Thorac Cardiovasc Surg.41:340-3, 1993.

RAO, A. B.; KOELLER, K. K.; ADAIR, C. F. Paragangliomas of the Head and Neck: radiologicpathologic correlation. From the archieves of the AFIP - continuing education, RSNA, v.19, n. 6, p. 1605-1632, 1999.

ROBBINS SL, COTRAN RS, KUMAR V. Patologia Estrutural e Funcional. $3^{a}$ ed. Rio de Janeiro: Guanabara; p. 1199, 1986.

SAMPAIO R.S., COELHO H.E., LACERDA M.S., OLIVEIRA P.C.L., PARO P.H.Z., REZENDE R.S. Efusão pleural secundária a tumor de corpo aórtico em cães: relato de 3 casos. Pesquisa Veterinária Brasileira. Instituto de Estudos Avançados em Veterinária "José Caetano Borges", Universidade de Uberaba. 2008.

SCHMID C, TJAN T, MOLLHOFF T, SCHOBER O, SCHELD HH. Recurrent bilateral carotid body tumors. A case report on a "typical" course of a rare disease. Thorac Cardiovasc Surg. 43:296-8. 1995.

SLATTER, D. Manual de cirurgia de pequenos animais. 2. a edição. São Paulo:

SOMA, F. L. et al. Estudo com Eco-Doppler, de tumor do corpo carotídeo. São Paulo: CETRUS, 2002. Disponível em: <http://www.cetrus.com.br/ler_publicacoes.asp?codigo=37 \&categoria $=\&$ menu $=$ Artigos $>$. Acesso em: 27 set. 2005.

SOUSA, A. V. et al. Tumores do corpo carotídeo. Arq. Neuropsquiatr. Rio de Janeiro, v. 58, n. 2-A, p. 315-323, 2000.

SOUZA, M.G.; ANDRADE, J.N.B.M. Neoplasias cardíacas. In: DALECK, C..R.; DENARDI, A.B. ; RODASKI, S. Oncologia em cães e gatos. 1. ed. São Paulo: Roca, p. 345-352, 2009.

SWENSON, M. J.; REECE, W. D. Fisiologia dos animais domésticos. 11. ed. Rio de Janeiro: Guanabara Koogan, p. 262-263, 1996.

WARE, W.A. Neoplasias cardíacas. In: TILLEY, L.P.; GOODWIN, J.K. Manual de Cardiologia para cães e gatos. 3.ed. São Paulo: Roca, p.249-258, 2002.

WILLIS, R. et al. Aortic Body Chemodectoma Causing Pulmonary edema in a cat. JSAP, v. 42, Jan. 2001.

YATES, W.D.G.; LESTER, S.J.; MILLS J.H.L. Chemoreceptor tumors diagnosed at the Western College of Veterinary Medicine 1967-1979. Canadian Veterinary Journal, v. 21, p.124-129, 1980.

ZIMMERMAN, K. L. et al. Mediastinal mass in a dog with syncope and abdominal distension. Veterinary Clinical Pathology, California, USA, v. 29, n. 1, p. 19-21, 2000. 